\title{
Structure-Selective Synthesis of Mesostructured/Mesoporous Silica Nanofibers
}

Jianfang Wang, ${ }^{\dagger}$ Jinping Zhang, ${ }^{\ddagger}$ Beverly Y. Asoo, ${ }^{\ddagger}$ and Galen D. Stucky ${ }^{\star},+, \neq$

Department of Chemistry and Biochemistry and Materials Department, University of California, Santa Barbara,

California 93106-9510

\section{Supporting Information}

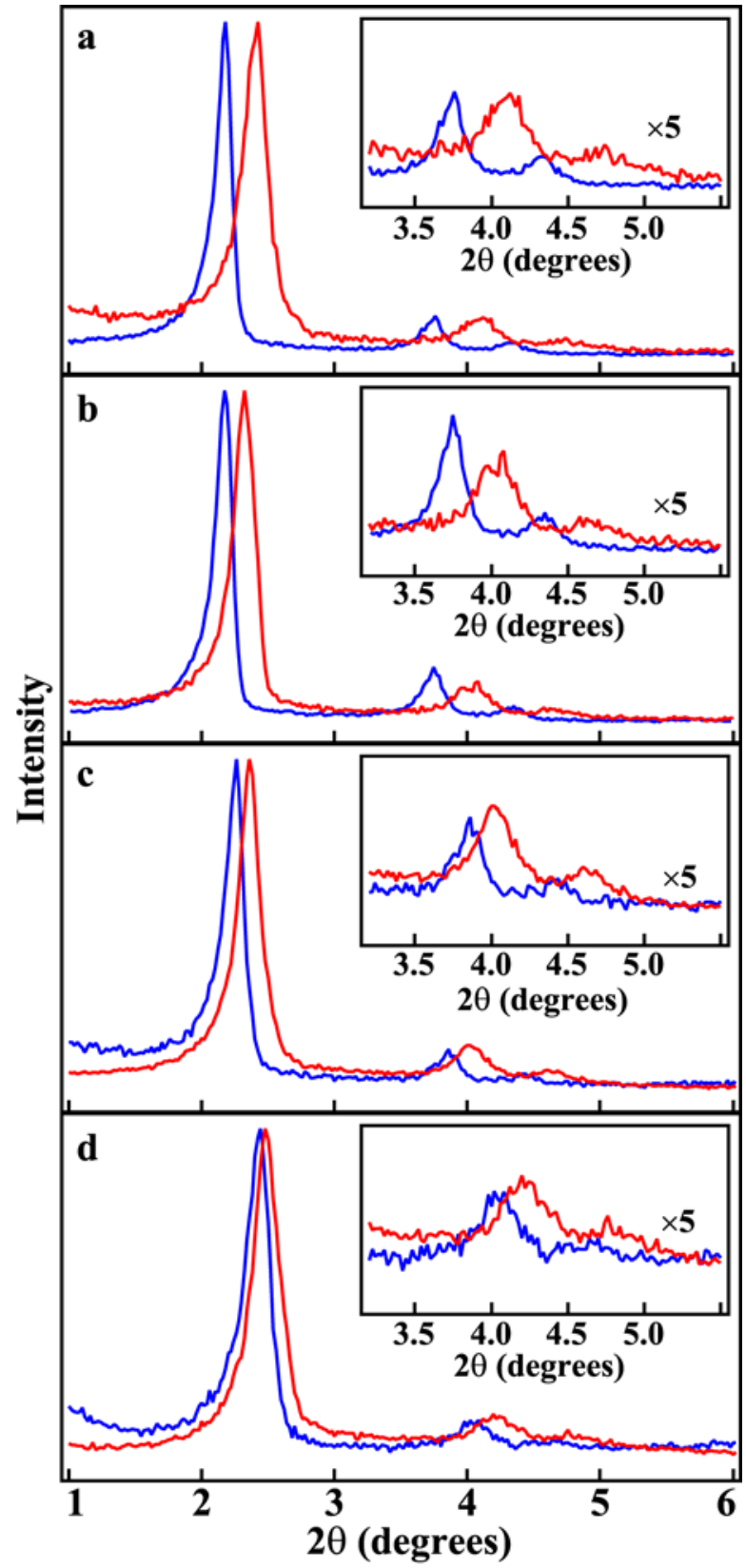

Figure S1. Low-angle X-ray diffraction (XRD) patterns. The intensity has been normalized to the strongest reflection. Blue and red curves represent as-synthesized and calcined samples, respectively. Calcination was carried out in air at $500^{\circ} \mathrm{C}$ for $4 \mathrm{~h}$ with a ramp rate of $1{ }^{\circ} \mathrm{C} / \mathrm{min}$. Three reflections are visible in all patterns. They can be indexed as (100), (110), and (200) reflections on a hexagonal lattice structure. (a) Nanofibers with the circular pore arrangement. As-synthesized: $d_{(100)}=4.052 \mathrm{~nm}, d_{(110)}=2.350$ $\mathrm{nm}, d_{(200)}=2.036 \mathrm{~nm}$. The average lattice constant is $a=4.7 \mathrm{~nm}$
Calcined: $d_{(100)}=3.651 \mathrm{~nm}, d_{(10)}=2.145 \mathrm{~nm}, d_{(200)}=1.849 \mathrm{~nm}$. The average lattice constant is $a=4.3 \mathrm{~nm}$. (b) Nanofibers with the longitudinal pore arrangement. As-synthesized: $d_{(100)}=4.071 \mathrm{~nm}, d_{(110)}=2.356 \mathrm{~nm}$, $d_{(200)}=2.031 \mathrm{~nm}$. The average lattice constant is $a=4.7 \mathrm{~nm}$. Calcined: $d_{(100)}=3.808 \mathrm{~nm}, d_{(110)}=2.187 \mathrm{~nm}, d_{(200)}=1.896 \mathrm{~nm}$. The average lattice constant is $a=4.4 \mathrm{~nm}$. (c) Particles grown at $80^{\circ} \mathrm{C}$. As-synthesized: $d_{(100)}$ $=3.909 \mathrm{~nm}, d_{(110)}=2.289 \mathrm{~nm}, d_{(200)}=1.990 \mathrm{~nm}$. The average lattice constant is $a=4.6 \mathrm{~nm}$. Calcined: $d_{(100)}=3.743 \mathrm{~nm}, d_{(110)}=2.198 \mathrm{~nm}, d_{(200)}$ $=1.908 \mathrm{~nm}$. The average lattice constant is $a=4.4 \mathrm{~nm}$. (d) Particles grown at $50^{\circ} \mathrm{C}$. As-synthesized: $d_{(100)}=3.621 \mathrm{~nm}, d_{(10)}=2.176 \mathrm{~nm}, d_{(200)}=1.888$ $\mathrm{nm}$. The average lattice constant is $a=4.3 \mathrm{~nm}$. Calcined: $d_{(100)}=3.562$ $\mathrm{nm}, d_{(110)}=2.104 \mathrm{~nm}, d_{(200)}=1.856 \mathrm{~nm}$. The average lattice constant is $a=$ $4.2 \mathrm{~nm}$. Low-angle XRD patterns were obtained on a Scintag PADX diffractometer using $\mathrm{Cu} \mathrm{K}_{\alpha}$ radiation 


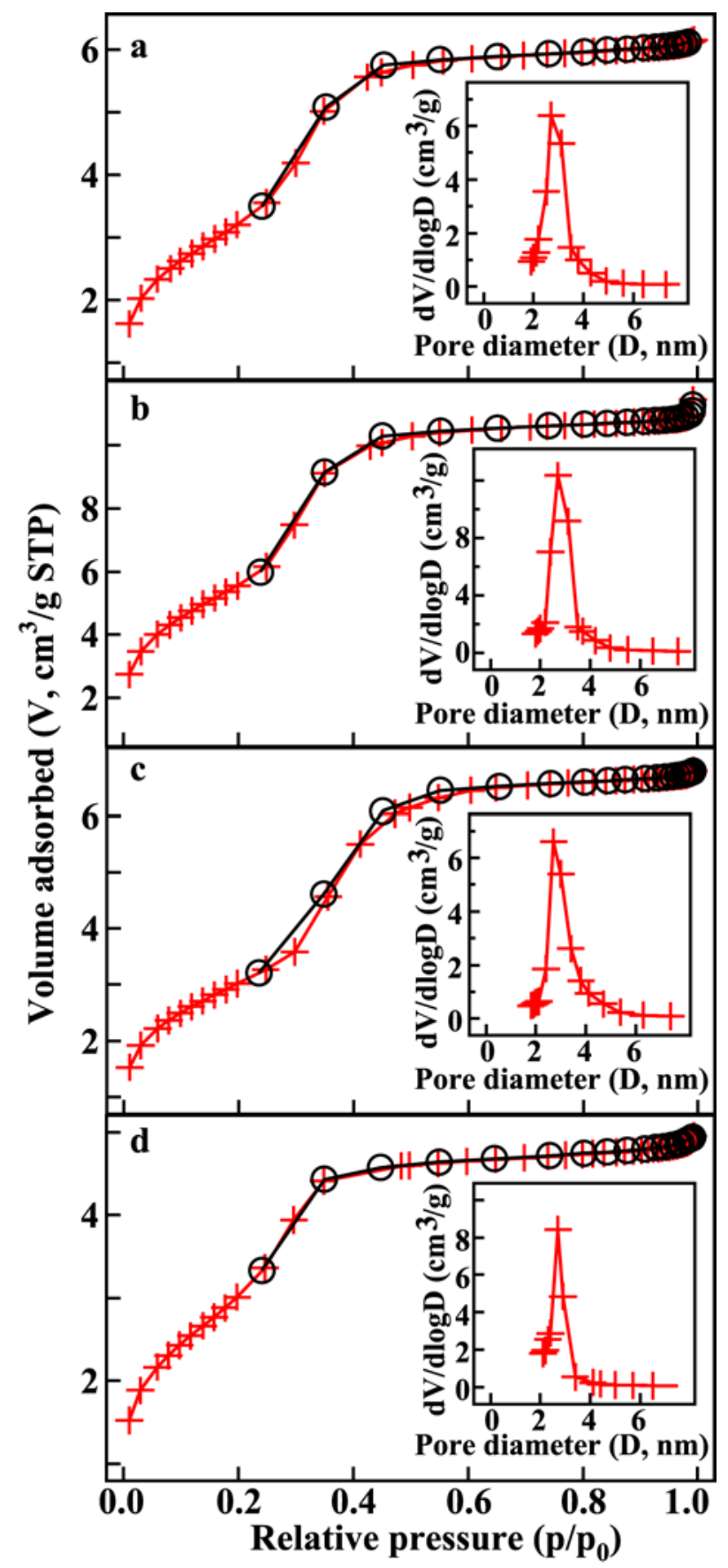

Figure S2. $\mathrm{N}_{2}$ adsorption-desorption isotherms measured on calcined samples. Red and black traces represent adsorption and desorption branches, respectively. The insets are corresponding pore size distributions. (a) Nanofibers with the circular architecture. BrunauerEmmett-Teller (BET) surface area is $1180 \mathrm{~m}^{2} / \mathrm{g}$. Single point desorption pore volume at $\mathrm{p} / \mathrm{p}_{0}=0.9774$ is $0.94 \mathrm{~cm}^{3} / \mathrm{g}$. Barrett-Joyner-Halenda (BJH) pore size is $2.7 \mathrm{~nm}$ with a full-width-at-half-maximum (FWHM) value of $0.9 \mathrm{~nm}$. (b) Nanofibers with the longitudinal architecture. BET surface area is $2050 \mathrm{~m}^{2} / \mathrm{g}$. Single point desorption pore volume at $\mathrm{p} / \mathrm{p}_{0}=0.9907$ is $1.72 \mathrm{~cm}^{3} / \mathrm{g}$. BJH pore size is $2.7 \mathrm{~nm}$ with a FWHM value of $0.8 \mathrm{~nm}$. (c) Particles grown at $80^{\circ} \mathrm{C}$. BET surface area is $1100 \mathrm{~m}^{2} / \mathrm{g}$. Single point desorption pore volume at $\mathrm{p} / \mathrm{p}_{0}=0.9907$ is $1.05 \mathrm{~cm}^{3} / \mathrm{g}$. BJH pore size is $2.7 \mathrm{~nm}$ with a FWHM value of $0.8 \mathrm{~nm}$. (d) Particles grown at $50^{\circ} \mathrm{C}$. BET surface area is $1100 \mathrm{~m}^{2} / \mathrm{g}$. Single point desorption pore volume at $\mathrm{p} / \mathrm{p}_{0}=$ 0.9905 is $0.76 \mathrm{~cm}^{3} / \mathrm{g}$. BJH pore size is $2.7 \mathrm{~nm}$ with a FWHM value of 0.5 $\mathrm{nm}$. The nitrogen adsorption and desorption isotherms at $77 \mathrm{~K}$ were measured using a Micromeritics TriStar system after the samples were vacuum-dried at $200^{\circ} \mathrm{C}$ overnight. The sorption data were analyzed using the BJH model. For the BJH analysis, the pore size distribution was obtained from the analysis of the adsorption branch of the isotherm.

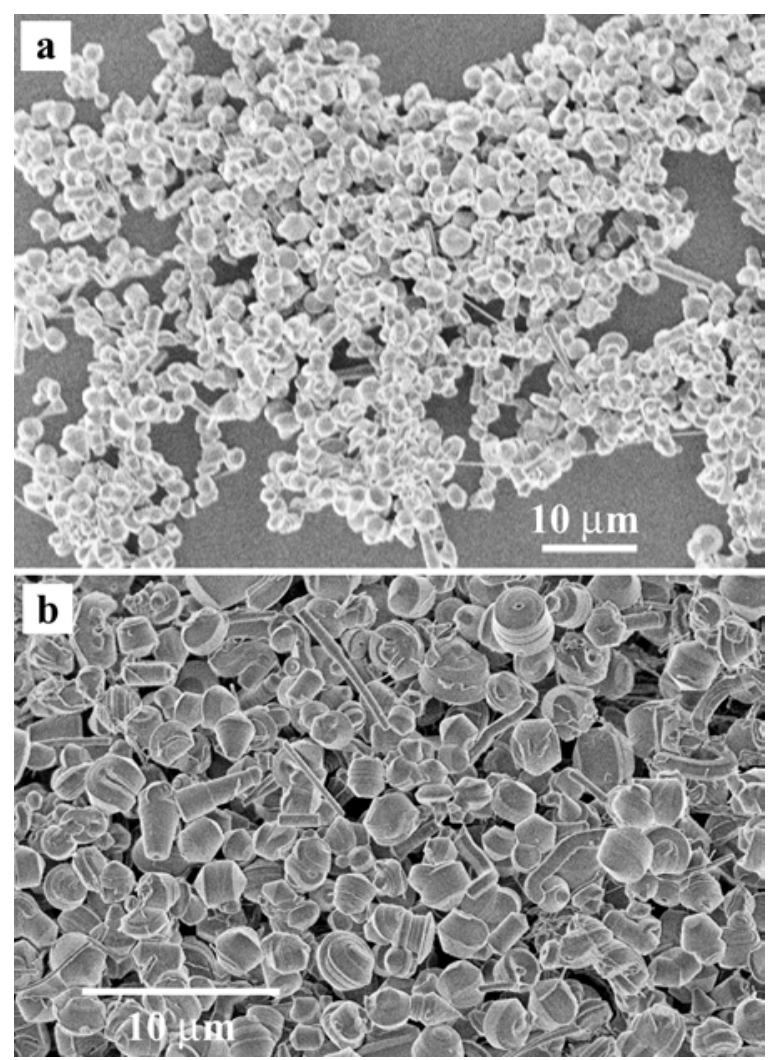

Figure S3. SEM images of mesostructured particles with curved morphologies. (a) The reaction composition in the molar ratio is $100 \mathrm{H}_{2} \mathrm{O}$ : $7 \mathrm{HCl}: 0.018 \mathrm{C} 16 \mathrm{TMACl}: 0.023$ TEOS and the growth temperature is $80^{\circ} \mathrm{C}$. (b) The reaction composition in the molar ratio is $100 \mathrm{H}_{2} \mathrm{O}: 7.2$ $\mathrm{HCl}: 0.018 \mathrm{C} 16 \mathrm{TMACl}: 0.024 \mathrm{TEOS}$ and the growth temperature is $50^{\circ} \mathrm{C}$. The reaction time for both samples is $4 \mathrm{~d}$. The particle sizes are larger than $\sim 1.5 \mu \mathrm{m}$. 

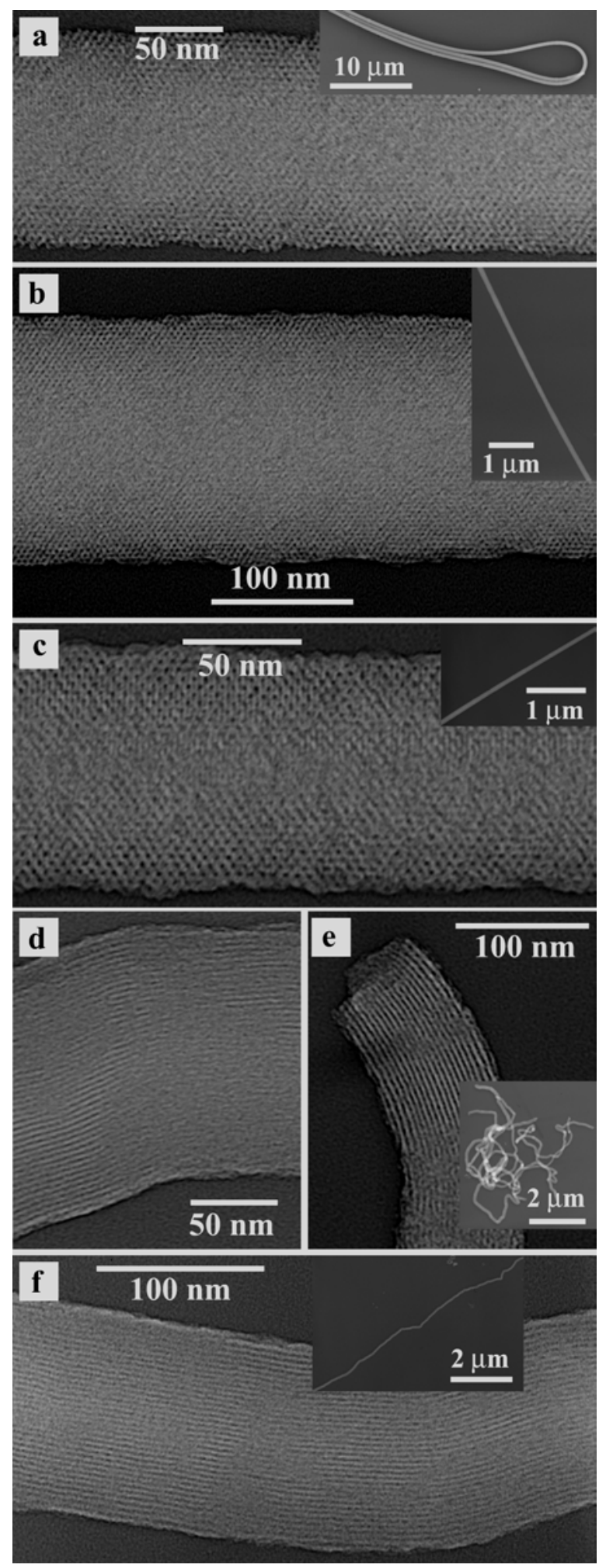

Figure S4. TEM images of typical mesostructured nanofibers synthesized under various conditions. (a) The reaction composition in the molar ratio is $100 \mathrm{H}_{2} \mathrm{O}: 7.1 \mathrm{HCl}: 0.016 \mathrm{C} 16 \mathrm{TMABr}: 0.022 \mathrm{TEOS}$ and the growth temperature is $80^{\circ} \mathrm{C}$. The diameter of the fiber is $120 \mathrm{~nm}$, and the pore-topore distance is $4.8 \mathrm{~nm}$. Inset is a low-magnification image of several nanofibers bundled together. (b) The reaction composition in the molar ratio is $100 \mathrm{H}_{2} \mathrm{O}: 7.1 \mathrm{HCl}: 0.017 \mathrm{C} 16 \mathrm{PCl}: 0.022$ TEOS and the growth temperature is $80^{\circ} \mathrm{C}$. The fiber diameter is $170 \mathrm{~nm}$ and the pore-to-pore distance is $4.5 \mathrm{~nm}$. Inset is a low-magnification image. (c) The reaction composition in the molar ratio is $100 \mathrm{H}_{2} \mathrm{O}: 7 \mathrm{HCl}: 0.016 \mathrm{C} 16 \mathrm{PBr}: 0.022$ TEOS and the growth temperature is $80^{\circ} \mathrm{C}$. The fiber diameter is $100 \mathrm{~nm}$ and the pore-to-pore distance is $4.8 \mathrm{~nm}$. Inset is a low-magnification image. (d) The reaction composition in the molar ratio is $100 \mathrm{H}_{2} \mathrm{O}: 7 \mathrm{HCl}$
$0.019 \mathrm{C} 16 \mathrm{TMACl}: 0.038$ TEOS : $0.19 \mathrm{~K}_{2} \mathrm{SO}_{4}$ and the growth temperature is $80^{\circ} \mathrm{C}$. The fiber diameter is $140 \mathrm{~nm}$ and the spacing between parallel pore channels is $3.4 \mathrm{~nm}$. (e) The reaction composition in the molar ratio is $100 \mathrm{H}_{2} \mathrm{O}: 7 \mathrm{HCl}: 0.0034 \mathrm{C} 18 \mathrm{TMABr}: 0.01 \mathrm{TEOS}$ and the growth temperature is $80^{\circ} \mathrm{C}$. The fiber diameter is $88 \mathrm{~nm}$ and the spacing between parallel pore channels is $4.2 \mathrm{~nm}$. Inset is a lowmagnification image. (f) The reaction composition in the molar ratio is $100 \mathrm{H}_{2} \mathrm{O}: 7 \mathrm{HCl}: 0.018 \mathrm{C} 16 \mathrm{TMACl}: 0.025$ TEOS : $0.00025 \mathrm{NaF}$ and the growth temperature is $80^{\circ} \mathrm{C}$. The fiber diameter is $120 \mathrm{~nm}$ and the spacing between parallel pore channels is $3.5 \mathrm{~nm}$. Inset is a low-magnification image.

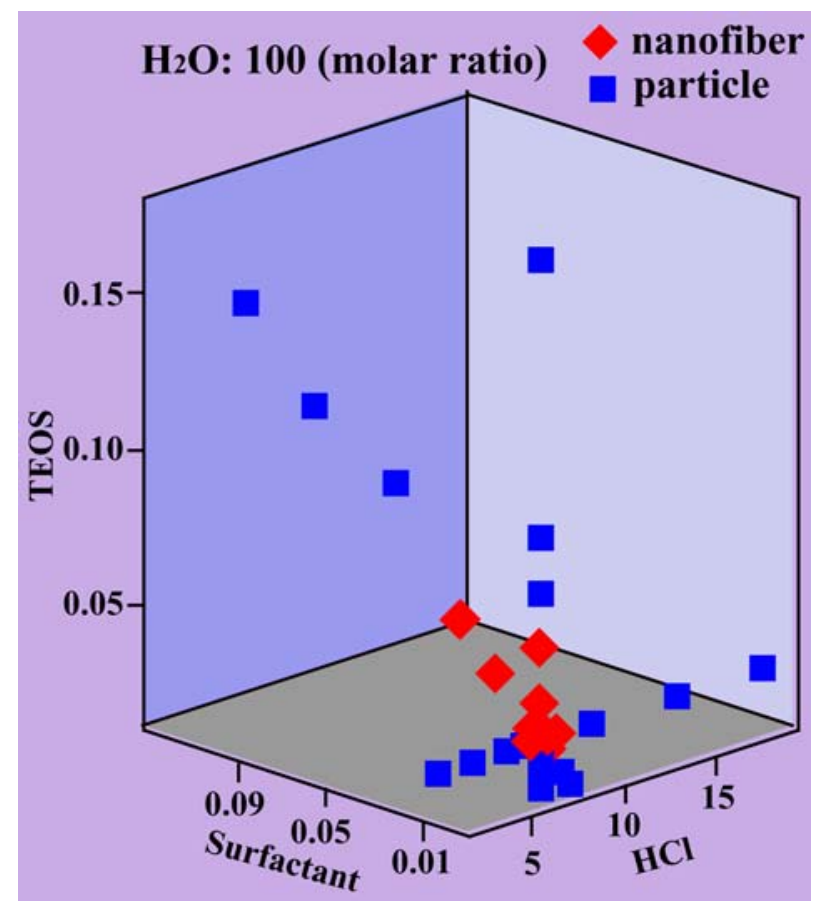

Figure S5. Reaction products under various conditions. The surfactant is $\mathrm{C} 16 \mathrm{TMACl}$. The growth temperature is $80^{\circ} \mathrm{C}$. Three axes represent the molar ratios of $\mathrm{HCl}, \mathrm{C} 16 \mathrm{TMACl}$, and TEOS relative to $100 \mathrm{H}_{2} \mathrm{O}$, respectively. Red diamonds denote that nanofiber flocculates and particles were obtained from the syntheses with indicated reaction compositions, and blue squares denote that only particles were obtained from the syntheses with indicated compositions.

Discussion. We focused on the use of $\mathrm{C} 16 \mathrm{TMACl}$ as the surfactant to vary the conditions for the synthesis of mesostructured silica nanofibers. The investigated synthesis parameters include the growth temperature, the concentrations of $\mathrm{HCl}$, surfactant, and TEOS, and the molar ratio between TEOS and surfactant. Fig. S5 summarizes the results from the syntheses at the growth temperature of $80^{\circ} \mathrm{C}$ with varying concentrations of $\mathrm{HCl}, \mathrm{C} 16 \mathrm{TMACl}$, and TEOS. Red diamonds denote that both nanofiber flocculates and particles were obtained from the syntheses with indicated reaction compositions, while blue squares denote that only particles were obtained from the syntheses with indicated compositions. Fig. S5 shows that the optimized reaction compositions for the one-phase synthesis of mesostructured nanofibers at $80^{\circ} \mathrm{C}$ are centered at $100 \mathrm{H}_{2} \mathrm{O}: 7$ $\mathrm{HCl}: 0.02 \mathrm{C} 16 \mathrm{TMACl}: 0.03$ TEOS (molar ratio). In contrast, previous two-phase syntheses of mesostructured fibers with diameters from 1 to $40 \mu \mathrm{m}$ have been conducted at room temperature with a typical reaction composition of $100 \mathrm{H}_{2} \mathrm{O}: 2.9$ $\mathrm{HCl}: 0.025$ C16TMABr : 0.054 TEOS. $^{4 \mathrm{~b}, 4 \mathrm{~d}}$ During the two-phase syntheses, silica precursors diffuse from the oil phase to the interface, where they are hydrolyzed. The resulting silica monomers and oligomers then assemble with surfactant molecules 
at the two-phase interface to form mesostructured products, the morphologies of which strongly depend on the silica supply and on the assembly process between silica and surfactant molecules at the interface. In our one-phase synthesis, silica monomers and oligomers are homogeneously dissolved in the water solution. The morphologies of the resulting products are determined by the assembly process between silica and surfactant molecules in the solution. This simple route offers the opportunity for further controlling the shape and pore orientation of mesostructured products.

We first tried growing nanofibers with the optimized reaction composition by systematically varying growth temperatures from room temperature to less than $100^{\circ} \mathrm{C}$. When the growth temperature was between $90^{\circ} \mathrm{C}$ and $100^{\circ} \mathrm{C}$ or between room temperature and $40^{\circ} \mathrm{C}$, no nanofibers were obtained. Growth at $~$ $80^{\circ} \mathrm{C}$ gave nanofibers with a circular architecture, while growth at $\sim 50^{\circ} \mathrm{C}$ gave nanofibers with a longitudinal architecture. Between these two temperatures, for example, $\sim 65^{\circ} \mathrm{C}$, a mixture of nanofibers with either a circular or a longitudinal architecture was obtained.

TEM imaging shows that nanofibers with a circular architecture are smooth and have uniform diameters along the fiber axis, while nanofibers with a longitudinal structure have small bends along the fiber axis (Fig. 1a, Fig. 2a, Fig. S4). This feature allows for rapidly examining the internal architectures of nanofibers using SEM, eliminating the need of time-consuming TEM imaging.

We extended the one-phase synthesis of nanofibers to $\mathrm{C} 16 \mathrm{TMABr}, \mathrm{C} 16 \mathrm{PCl}$, and $\mathrm{C} 16 \mathrm{PBr}$, which have the same carbon chain length as $\mathrm{C} 16 \mathrm{TMACl}$. The syntheses using these surfactants also produce mesostructured nanofibers, as shown in Fig. S4a, b, and c. Inorganic salts, such as $\mathrm{NaF}, \mathrm{NaCl}, \mathrm{NaBr}, \mathrm{K}_{2} \mathrm{SO}_{4}$, and $\mathrm{KNO}_{3}$, were also used as additives in order to control the internal architectures of nanofibers. At the growth temperature of $80^{\circ} \mathrm{C}$, the ratio between fluoride salts and silica needed to change the architecture from circular to longitudinal is in the range of $0.002-$ 0.01 (Fig. S4f), while the concentrations of non-fluoride salts required to change the internal architecture are in the range of $0.006-0.1 \mathrm{M}$, depending on specific salts (Fig. S4d). The difference in the concentrations of fluoride and non-fluoride salts required to induce a structure change is due to the fact that fluoride anions can catalyze silica condensation and that the presence of a small amount of fluoride anions can greatly promote the linear chain growth of silica.

We further tried cationic ammonium bromide surfactants with varying chain lengths to synthesize nanofibers. Interestingly, the syntheses using $\mathrm{C} 18 \mathrm{TMABr}$ always produce nanofibers without any particles at the growth temperature of $80^{\circ} \mathrm{C}$, and the nanofibers always have pore channels oriented parallel to the fiber axis (Fig. S4e). When the growth temperature is lower than $60^{\circ} \mathrm{C}$, no nanofibers can be obtained. When using $\mathrm{C} 12 \mathrm{TMABr}$ and $\mathrm{C} 14 \mathrm{TMABr}$ as surfactants, micrometer-sized mesostructured spheres and facet-shaped rods have been obtained. The dependence of the morphology on the surfactant chain length will be treated in a future publication.

We believe that the growth of mesostructured nanofibers involves two stages. The first stage is the assembly between silica and surfactant molecules to form nucleation sites. The second stage is continuous growth of nucleation sites into nanofibers. The internal architectures of grown mesostructured nanofibers are controlled in the first stage by the cooperative assembly process and its associated free energy changes. The free energies involved in the cooperative nucleation of molecular silica species with surfactant molecules have been described previously ${ }^{2 b}$ to be composed of four contributions of (i) van der Waals and electrostatic interactions at the interface of inorganic silica and organic surfactant phases, (ii) interactions within the silica wall, (iii) van der Waals forces and conformational energies of the surfactant hydrocarbon chains and van der Waals and electrostatic interactions of the surfactant head groups, and (iv) the chemical potential of the surrounding solution phase. The free energy associated with the organization of surfactant molecules varies with the growth temperature and the addition of inorganic salts, as evidenced by previous observations that the critical micelle concentrations (cmc) of cationic alkyltrimethylammonium halide surfactants increase with increasing temperature and decrease with the addition of inorganic salts (van Os, N. M.; Haak, J. R.; Rupert, L. A. M. Physico-Chemical Properties of Selected Anionic, Cationic, and Nonionic Surfactants; Elsevier: New York, 1993). The addition of inorganic salts into the growth solution can also moderate the electrostatic interactions between surfactant molecules and charged silica species and change the chemical potential of the growth solution. As a result, the cooperative assembly between surfactant molecules and silica species produces nucleation sites with different internal architectures in order to minimize the overall free energy of the growth system. The minimization of the overall free energy is also manifested by the observations that the nanofibers with a circular architecture have a round cross section and that the nanofibers with a longitudinal architecture have a hexagonal cross section. The external surface area of the cylindrical fibers is $\sim 95 \%$ of that of the hexagonal fibers at a constant cross-section area. The interior packing energy of mesostructured domains in the hexagonal nanofibers with a longitudinal architecture must somehow compensate for the increase in the surface energy. Further efforts are required to make a quantitative analysis of the temperature and salt effects on the free energies involved in the assembly of mesostructured nanofibers. 